\title{
Does financial development cause economic growth? A panel data dynamic analysis for the Asian developing countries
}

\begin{abstract}
This paper examines the causal relationship between financial development and economic growth of the Asian developing countries from a panel data perspective and uses the system GMM technique developed by Arellano \& Bover (1995) and Blundell \& Bond (1998) and conducts causality testing analysis. The panel data sets involve 13 Asian developing countries: Bangladesh, India, Indonesia, South Korea, Lao PDR, Malaysia, Myanmar, Nepal, Pakistan, Philippine, Singapore, Sri Lanka and Thailand for the period 1990-1998. The result of our study is in agreement with other causality studies by Calderon \& Liu (2003), Fase \& Abma (2003), and Christopoulos \& Tsionas (2004) that financial development promotes growth, thus supporting the old Schumpeterian hypothesis and Patrick's supply-leading' hypothesis.
\end{abstract}

Keyword: Asian countries, Demand-following, Finance-growth nexus, Supply-leading 